\title{
ORGANISATIONAL BEHAVIOUR IN HUMAN RESOURCE DEVELOPMENT
}

\author{
Dr.CK GOMATHY, Mr. KATTEBOYINA HARI SANKAR, Mr. J HRUDAY VIKAS , KOLLU NISHANTH REDDY
}

Sri Chandrasekharendra Saraswathi Viswa Mahavidyalaya, Kanchipuram

\begin{abstract}
Organizational behaviour is a discipline of social science that look for explanations for human behaviour in organizations. Organisational behaviour draws on core disciplines such as psychology, sociology, anthropology, economics, communication, and law to create and investigate multilevel explanations of why people take part in particular behaviour, and which behaviour under which situation lead to better outcomes in organizations. Created using an applied or pragmatic lens and tested with a wide range of both quantitative and qualitative methodologies, most Organisational behaviour theories and research have direct implications for managers and for other organizational participants. Not surprisingly, one focal area of Organisational behaviour research concerns safety in organizations, and a growing body of safety-oriented literature in Organisational behaviour is based on data collected during simulation training across a variety of organizations such as hospitals, airlines, nuclear power plants, and other high reliability organizations.
\end{abstract}

Keywords: Organizational Behaviour, Human Resource Management, Human Behaviour

\section{INTRODUCTION}

In this unit we tend to are reaching to apprehend the fundamental ideas of organisational behaviour and its impact on the worldwide situation. we tend to study the individual factors like temperament, attitude, learning, perception, motivation and skill with relation to structure behaviour and commitment.

Organizational Behaviour is outlined because the understanding, prediction and management of human behaviour each singly or during a cluster that occur inside a organisation.

Internal and external views area unit the 2 theories of however organisational behaviour may be read from an organization's purpose of view. during this tutorial, we are going to be learning well concerning each the theories.

\section{IMPORTANCE OF ORGANISATIONAL BEHAVIOUR}

While operating in a corporation, it's vital perceive to know others behaviour still as create others understand ours. so as to keep up a healthy operating surroundings, we want to adapt to the surroundings and perceive the goals we want to attain. This will be done simply if we tend to perceive the importance of Organisational behaviour. 


\section{Following points bring out the importance of Organisational behaviour}

- It helps in explaining the interpersonal relationships employees share with each other as well as with their higher and lower subordinates.

- The prediction of individual behaviour can be explained.

- It balances the cordial relationship in an enterprise by maintaining effective communication.

- It assists in marketing.

- It helps managers to encourage their sub-ordinates.

- Any change within the organization can be made easier.

- It helps in predicting human behaviour \& their application to achieve organizational goals.

- It helps in making the organisation more effective.

Thus finding out organisational behaviour helps in recognizing the patterns of human behaviour and successively throw lightweight on however these patterns deeply influence the performance of a company. Organizational behaviour is outlined because the systematic study and application of data concerning however people and teams act inside the organizations wherever they work.

\section{MEANING AND DEFINITION OF ORGANISATIONAL BEHAVIOUR}

Organisational behaviour is concerned with people's thoughts, feelings, emotions, and actions in a work setting. Understanding an individual behaviour is in itself a challenge, but understanding group behaviour in an organisational environment is a monumental managerial task. As Nadler and Thushman put it: "understanding one individual's behaviour is challenging in and of itself; understanding a group that is made up of different individuals and comprehending the many relationships among those individuals is even more complex. Ultimately, the organisation's work done by people, individually or collectively, on their own or in collaboration with technology. Therefore, the management of organisational behaviour is central to the management task - a task that involves the capacity to "understand" the behaviour patterns of individuals, groups and organisations, to "estimate" what behavioural responses will be elicited by various managerial actions and finally to use this understanding and these predictions to achieve "control".

\section{ELEMENTS OF ORGANISATIONAL BEHAVIOUR}

The key elements in the organisational behaviour are people, structure, technology and the environment in which the organisation operates.

People: People make up the internal and social system of the organisation. They consists of individuals and groups. The groups may be big or small; formal or informal; official or unofficial. Groups are dynamic. They work in the organisation to achieve their objectives.

Structure: Structure defines the formal relationships of the people in organisations. Different people in the organisation are performing different type of jobs and they need to be related in some structural way so that their work can be effectively co-ordinated.

Technology: Technology such as machines and work processes provide the resources with which people work and affects the tasks that they perform. The technology used has a significant influence on working relationships. It allows people to do more and better work but it also restricts people in various ways. 
Environment: All organisations operate within an external environment. It is part of a larger system that contains many other elements such as government, the family and other organisations. All of these mutually influence each other in a complex system that creates a context for a group of people.

\section{INDIVIDUAL BEHAVIOUR}

Human behaviour, a complex phenomenon as it is, is most difficult to define in absolute terms. It is primarily a combination of responses to external and internal stimuli. These responses would reflect psychological structure of the person and may be a result of combination of biological and psychological processes, interprets them, responds to them in an appropriate manner and learns from the result of these responses. Psychologist Kurt Levin has conducted considerable research into the human behaviour and its causes. He believes that people are influenced by a number of diversified factors, both genetic and environmental, and the influence of these factors determines the pattern of behaviour. Whenever people buy something, for example, a car, both the buyer and the seller sign a contract that specifies the terms of the sales agreement. Similarly, most people, when they begin a working relationship with an organisation formulate a psychological contract with their employer. A psychological contract is the overall set of expectations that an individual holds with respect to his/her contributions to the organisation and the organisation's response to those contributions. A psychological contract is not written down like a legal contract. The individual makes a variety of contributions to the organisation - effort, skills, ability, time, loyalty and so forth. These contributions presumably satisfy various needs and requirements of the organisation. In return for contributions, the organisation provides inducements such as pay, promotion, job security, etc. to the individual. Just as the contributions available from the individual must satisfy the organisation's needs, the inducements must serve the individual's needs.

\section{ORGANISATIONAL COMMITMENT AND INVOLVEMENT}

Two different vital work-related attitudes area unit organisational commitment and involvement. Organisational commitment is that the individual's feeling of identification with and attachment to an organisation. Involvement refers to a person's disposition to be a team member and work on the far side the standard standards of the task. AN worker with very little involvement is intended by adventitious psychological feature issue and an worker with sturdy involvement is intended by intrinsic psychological feature factors. variety of things result in commitment and involvement. Each could increase with employee's age and years with the organisation, sense of job security and participation in decision making. If the organisation treats its workers fairly and provides affordable rewards and job security, workers area unit additional probably to be glad and committed. Involving workers in decision-making also can facilitate to extend commitments. Above all, planning jobs that area unit fascinating and stimulating will enhance job involvement.

\section{MOTIVATION}

The word motivation comes from the word 'motive' that is outlined as a lively kind of a need, desire or want that should be glad. Motivation is that the key to organisational effectiveness. The manager normally has got to get the work done through others. These 'others' are human assets or resources. they're to be intended to figure to achieve the organisational objectives. 
Importance of Motivation: Motivation is an important part of managing process. A team of highly qualified and motivated employees is necessary for achieving objectives of an organisation. It is only through motivation process, they contribute maximum for accomplishing objectives.

The motivation framework is a good starting point for understanding how people choose certain behaviours. The motivation process begins with needs that individuals identify for themselves. For example, a worker feels that he is underpaid. This deficiency becomes a need that the worker seeks to satisfy, perhaps, by asking for a raise, by working harder to earn a raise or by seeking a new job. Once he chooses to pursue one or more of these options and then enacts them (working harder while simultaneously looking for a job, for example), he evaluates his success. If his hard work resulted in a pay rise, he probably feels satisfied and will continue to work hard. But if no raise has been provided he is likely to try another option. Since people have many different needs, the satisfaction of one need or set of needs is likely to give rise to the identification of other needs. Thus, the cycle of motivation is being constantly repeated. Understanding human motivation is crucial for managing people. Many people have done extensive research to find out what make people work and how to motivate them. This include managers, social scientists, behaviourists and psychologists. A number of theories have been developed, even though there is no university accepted motivation theory. Understanding these theories assist managers to get a better insight into the human behaviour.

\section{CONCLUSION}

The study of organizational behaviour is one of the most significant elements in the management sciences, as it makes management learn from what has succeeded elsewhere. Generally, financial strength is a measure of the organizations past success. What determines whether the organization will continue to deliver sought-after products, will continue to develop cutting edge technology, will continue to make the right options about which direction the market is going to go, will continue to make sound investments, is the people and the organizational culture and structure.

Different organizational structures will show different types of organizations that each has strengths and weaknesses. Human beings encourage seeking satisfaction in every phase of their life. From satisfying their basic primal needs and wants, which is hunger, thirst, rest and social interaction, the complex community today has its benchmark of goals and fulfilment that should be accomplished by individuals. This selective set of fulfilment and goals encloses securing a good job, preferably with a good pay and hopefully, with a high level of job satisfaction. There is no fixed and formal guideline on how to overcome challenges at work into a motivation for individuals to reach job satisfaction, so that with the good practicing of organizational behaviour development, individuals are able to well handle the task pressure, and overcome the variety of challenges.

Organizational Behaviour is the application of knowledge about how peoples, individuals, and groups act and react in an organization, in order to reach and accomplish the highest quality of performances, and dominant results. One way for an organization to become more innovative is to capitalize on its own employee's to innovate. All organizations and groups experience the direct relationship between job satisfaction, and performance. In order to maximize the performance of those within a system, it is significant important to develop an optimal interpersonal chemistry 


\section{IX.REFERENCES}

[1] C.K.Gomathy.(2010),"Cloud Computing: Business Management for Effective Service Oriented Architecture" International Journal of Power Control Signal and Computation (IJPCSC), Volume 1, Issue IV, Oct - Dec 2010, P.No:22-27, ISSN: 0976-268X .

[2] Dr.C K Gomathy, Article: A Study on the recent Advancements in Online Surveying , International Journal of Emerging technologies and Innovative Research ( JETIR) Volume 5 | Issue 11 | ISSN : 2349-5162, P.No:327-331, Nov-2018

[3] Dr.C.K.Gomathy,C K Hemalatha, Article: A Study On Employee Safety And Health Management International Research Journal Of Engineering And Technology (Irjet)- Volume: 08 Issue: 04 | Apr 2021

[4] Dr.C K Gomathy, Article: A Study on the Effect of Digital Literacy and information Management, IAETSD Journal For Advanced Research In Applied Sciences, Volume 7 Issue 3, P.No-51-57, ISSN NO: 2279-543X,Mar/2018

[5] Dr.C K Gomathy, Article: An Effective Innovation Technology In Enhancing Teaching And Learning Of Knowledge Using Ict Methods, International Journal Of Contemporary Research In Computer Science And Technology (Ijcrcst) E-Issn: 2395-5325 Volume3, Issue 4,P.No-10-13, April 2017

[6] Dr.C K Gomathy, Article: Supply chain-Impact of importance and Technology in Software Release Management, International Journal of Scientific Research in Computer Science Engineering and Information Technology ( IJSRCSEIT ) Volume 3 | Issue 6 | ISSN : 2456-3307, P.No:1-4, July-2018.

\section{AUTHOR'S PROFILE}

Mr.KATTEBOYINA HARI SANKAR Student, B.E. (Computer Science and Engineering), Sri Chandrasekharendra Saraswathi Viswa Maha Vidhyalaya, Enathur, Kanchipuram, India. His area of interest in Softeare Development and Human Resources Development.

Mr. J HRUDAY VIKAS Student, B.E. (Computer Science and Engineering), Sri Chandrasekharendra Saraswathi Viswa Maha Vidhyalaya, Enathur, Kanchipuram, India. His area of interest in Softeare Development and Human Resources Development.

Dr. C.K.Gomathy is Assistant Professor in Computer Science and Engineering at Sri Chandrasekharendra Saraswathi Viswa Maha Vidyalaya, Enathur, Kanchipuram, India. Her area of interest in Software Engineering Web Services, Knowledge Management and IOT. 